\title{
Ref-LitPsy Module: A Literacy-Psychospiritual Module for Refugees
}

Hazlina Abdullah, Suraini Mohd Ali, Dini Farhana Baharudin, Hazleena Baharun, Habibah Ismail, Fariza Puteh Behak, Noor Saazai Mat Saad, Mohd. Zaliridzal Zakaria, Rodziana Mohamed Razali

To Link this Article: http://dx.doi.org/10.6007/IJARBSS/v12-i1/11927 DOI:10.6007/IJARBSS/v12-i1/11927

Received: 13 November 2021, Revised: 16 December 2021, Accepted: 26 December 2021

Published Online: 18 January 2022

In-Text Citation: (Abdullah et al., 2022)

To Cite this Article: Abdullah, H., Ali, S. M., Baharudin, D. F., Baharun, H., Ismail, H., Behak, F. P., Saad, N. S. M., Zakaria, M. Z., \& Razali, R. M. (2022). Ref-LitPsy Module: A Literacy-Psychospiritual Module for Refugees. International Journal of Academic Research in Business and Social Sciences, 12(1), 889-909.

Copyright: @ 2022 The Author(s)

Published by Human Resource Management Academic Research Society (www.hrmars.com) This article is published under the Creative Commons Attribution (CC BY 4.0) license. Anyone may reproduce, distribute, translate and create derivative works of this article (for both commercial and non0-commercial purposes), subject to full attribution to the original publication and authors. The full terms of this license may be seen at: http://creativecommons.org/licences/by/4.0/legalcode

Vol. 12, No. 1, 2022, Pg. $889-909$

Full Terms \& Conditions of access and use can be found at http://hrmars.com/index.php/pages/detail/publication-ethics 


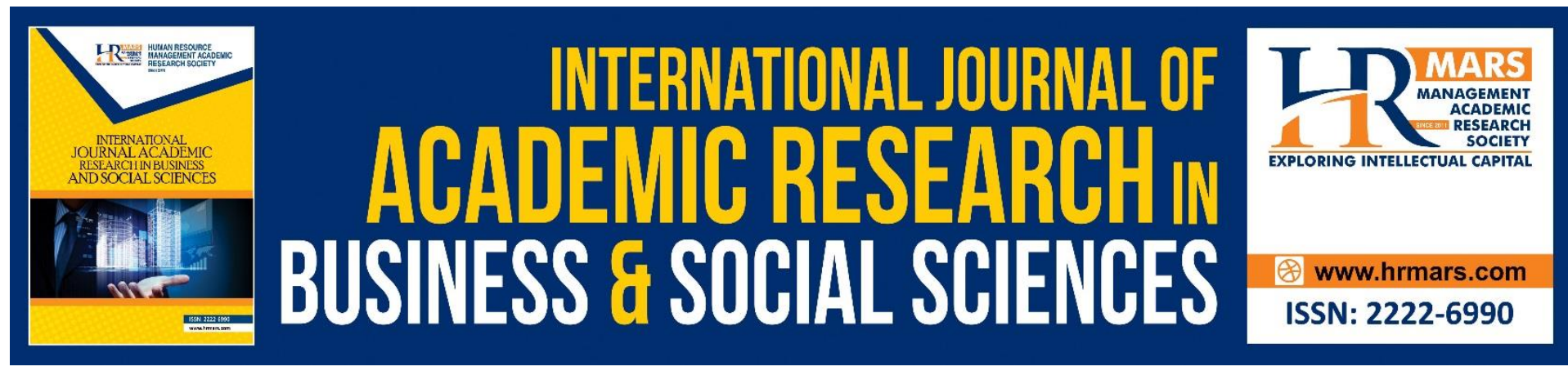

\title{
Ref-LitPsy Module: A Literacy-Psychospiritual Module for Refugees
}

\author{
Hazlina Abdullah ${ }^{1}$, Suraini Mohd Ali², Dini Farhana Baharudin ${ }^{3}$, \\ Hazleena Baharun ${ }^{4}$, Habibah Ismail ${ }^{5}$, Fariza Puteh Behak ${ }^{6}$, \\ Noor Saazai Mat Saad ${ }^{7}$, Mohd. Zaliridzal Zakaria ${ }^{8}$, Rodziana \\ Mohamed Razali ${ }^{9}$ \\ 1,2,4,5,6,7 Faculty of Major Language Studies, Universiti Sains Islam Malaysia, Bandar Baru Nilai, \\ Nilai, Negeri Sembilan, Malaysia, ${ }^{3,8}$ Faculty of Leadership and Management, Universiti Sains \\ Islam Malaysia, Bandar Baru Nilai, Nilai, Negeri Sembilan, Malaysia, ${ }^{9}$ Faculty of Shariah and \\ Law, Universiti Sains Islam Malaysia, Bandar Baru Nilai, Nilai, Negeri Sembilan, Malaysia. \\ Corresponding Author Email: hazlina@usim.edu.my
}

\begin{abstract}
Despite the aspiration of the United Nations' Sustainable Development Goal 4 (SDG4) which aims to provide inclusive and quality education for all, refugees remain to be left behind. Therefore, a support mechanism for this group of people is necessary. A baseline literacy study was conducted with 15 Rohingya youth refugees using a snowball sampling technique. Both qualitative and quantitative data collection instruments were used: baseline tests, interviews, and guided questionnaires. Following the findings, a framework emerged and was used as a guide for module development. The Ref-LitPsy Module aims to help youth refugees, specifically the Rohingyas, to function better in Malaysia as their host country. This researchbased module comprises two main components: a) Literacy and b) Psychospiritual. The former addresses basic English literacy specifically for non-Roman alphabetical background refugees while the latter assists refugees to cope with stress and losses associated with migration, and also to groom them in helping their community. This paper focuses on the first component, Literacy. The Ref-LitPsy module is divided into twelve structured units that are applied in psychospiritual counselling approach. The Ref-LitPsy module is beneficial for the long-term resettlement success of refugees by grooming social navigators to help themselves and the refugee community.
\end{abstract}

Keywords: Refugees, Social Navigation Training, Literacy, Psychospiritual, Module

\section{Introduction}

Refugees are "people who have fled war, violence, conflict or persecution and have crossed an international border to find safety in another country" (UNHCR, 2011-2021). According to UNHCR (2021), as of end July 2021, there are some 179,450 refugees and asylum-seekers registered with UNHCR in Malaysia and the majority are from Myanmar with some 102,960 Rohingyas, 22,490 Chins, and 29,390 other ethnic groups. The remaining are some 24,590 refugees and asylum-seekers from 50 countries fleeing war and persecution. 
From these statistics, $68 \%$ of refugees and asylum-seekers are men, while $32 \%$ are women and some 45,810 children are below the age of 18 . Coming from various regions globally with their own cultural, religious, linguistic, home practices and age groups, refugees often face issues of trust, language barrier, acceptance, and employability in their host countries (Ghazali et al., 2020; Nungsari \& Flanders, 2018). Often, they depend very much on their community leaders for social assistance. Unfortunately, the number of community leaders are insufficient to go around, leading to a pressing issue of who else can become social navigators to assist these refugee communities? Marshall (2016) highlights that youth refugees possess perspectives and knowledge that can contribute greatly to building inclusive communities and that the potentials should be tapped and nurtured. Building on this, it is believed that youth refugees can and should be trained to function as Social Navigators in their respective communities.

A baseline study conducted by Suraini et al. (2020) to investigate the English language literacy level of the Rohingya youth refugees in Malaysia identified several pertinent problems faced by the refugees in relation to their functional literacy skills. Firstly, the refugees had zero English language proficiency and they use different alphabetical system in their home country. Findings also revealed that despite the keen interests in acquiring English language proficiency, due to the different alphabetical systems, it was challenging for them to learn. This can cause difficulty to them as youth refugees in Malaysia rely on 'linguistic and social capital to negotiate Malaysian and refugee identities' (Lee, 2020, p.82; Lee \& Don, 2021). Thus, a module, known as the Ref-LitPsy Module: An Integrated Literacy-Psychoeducational Module for Youth Refugees to nurture and develop youth refugees to become social navigators for their communities is designed.

\section{Re-LitPsy Module: An Integrated Literacy-Psychoeducational Module for Youth Refugees}

The Re-LitPsy module, an integrated literacy- psychoeducational module is developed to help youth refugees, specifically the Rohingyas, to function better in Malaysia as their host country. It also aims to equip the refugees with basic literacy using psychospiritual counselling approach which will help them to improve language literacy and at the same time feel cared for. This module emphasises both knowledge and skills with the focus on two components: a) Literacy component and b) Psychospiritual component. The Literacy component addresses basic English literacy. It is specifically designed for non-Roman alphabetical background refugees while the Psychospiritual component assists refugees to cope with stress and losses associated with migration. The module is divided into twelve structured psychoeducation sessions that are applied in group counselling format. This module is also in line with the UN Sustainable Developmental Goals (SDGs) which aim to ensure inclusive and equitable quality education and promote lifelong learning opportunities for all. Not only can the implementation of the module be beneficial for long-term resettlement success of refugees in Malaysia, but the refugees can also at least be assisted and feel less threatened in the new culture they are in.

\section{Literature Review}

Rohingyas refugees crossed into Malaysia because they believe they will get a safe shelter given that they share Islam as their common religion with the Malaysians. Nevertheless, education is a part of the challenge of being a refugee in Malaysia. Refugee children have only limited access to it. If they want to study in the local government schools, they will have to pay higher for fees compared to the locals (Khairi, 2010). Apart from that, 
the adult refugees with limited education are a distinctive learner group with substantial and distinctive educational, social, and psychological needs. Refugees are therefore often identified as a high-need target group for educational interventions. This need is argued for both children and adults (Benseman, 2014). Furthermore Benseman (2014) also asserted that for those refugee adults with minimal or no schooling experience, the need is primarily centred on their lack of literacy skills (including English language), often complicated by the fact that many are not literate in their first languages.

Learning experience and literacy play a major role in this context, seeing that they form the basis for understanding written language and for the systematic acquisition of a new language by textbooks. People learning a second alphabet and those without literacy skills in any alphabet are therefore in different starting positions, both in comparison to each other and in comparison, to literates in the Latin alphabet. In contrast to people without literacy skills in any alphabet, those learning a second alphabet can fall back on learning strategies and writing skills they have acquired before (Scheible, 2018).

The United Nation High Commission for Refugee (UNHCR) stated that education is not only a fundamental human right but also an essential component of refugee and their children's rehabilitation. Research have indicated that education is crucial for restoring social and emotional healing among these refugees (McBrien, 2005). There is also some research evidence (Strategic Social Policy Group, 2008) that shows that becoming literate in the host country's language is essential for making friends outside their own community, finding, and sustaining employment, as well as maintaining social and psychological well-being (Benseman, 2014). Alternative pathways to education will be accessible in situations where formal academic education within national systems does not meet the learning needs of displaced or stateless children and youth and their host communities. Social inclusion approaches that focus on social adaptation and integration building of social capital are effective in successful refugee resettlement, which they defined as 're-establishing feelings of control' and that life is 'back to normal' (Mitschke et al., 2017). This includes access to dedicated programming to address missed schooling and language differences and literacy programmes, linked with national literacy initiatives accredited (UNHCR, 2019). Wardeh \& Marques (2021) explained that to connect SDG4 to reality, a comprehensive approach that considers education as a significant service is needed, in addition to emergency relief, highlighting the importance of inclusive and quality education with an integration program that are meeting the physical needs of refugees and simultaneously engaging in content that can ensure mental health stability.

Literacy skills are essential to accessing materials and media for further learning. Without literacy, the refugees especially their children will struggle in all academic areas (Wofford \& Tibi, 2018). Language barriers are, however, more complex than simply issues of interpretation and include recognition of literacy levels. Although this typically depends on the country of origin, refugees may have greater issues with literacy than other immigrants (e.g. Brown et al., 2006; Dewitt and Adelson, 2007; Folinsbee et al., 2007) if they are more likely to have a limited command of the English language. In contrast to people without literacy skills in any alphabet, those learning a second alphabet can fall back on learning strategies and writing skills they have acquired before (Wofford \& Tibi, 2018).

Although not unique to refugees, language difficulties and the need for interpretation services are consistently noted as one of the key barriers to health care and have been noted to be one of the most significant barriers to accessing care (McKeary \& Newbold, 2010). When 
discussing applicable interventions for mental health care and treatment among resettled refugees, one must consider the general mode of delivery, type of intervention, and purported effectiveness (Mitschke et al., 2017). Even more pressing than financial literacy concerns was the need for English language literacy assistance, their inability to understand English and the challenges they faced in adjusting to life challenges. On that note, Mitschke et al (2017) also mentioned that the refugees believe that English language and literacy education should be delivered to refugees.

Language is not just a refugee issue. But refugees are more likely to be illiterate, to have a limited command of the English language. In the case of Malaysia as the host country for Rohingya refugees, language and literacy problems that the refugees encounter, are mainly because of the dissimilar alphabetical language system they use as compared to the ones used in Malaysia. In Malaysia, both the national language and the second language (Malay and English languages) are Roman alphabetical languages. Contrariwise, the Rohingyas use a language of non-roman alphabetical background (written mother-tongue language without roman alphabets). This difference has caused the learning of both Malay and English languages a little hard. The focus on language and literacy due to low exposure in the host country's first and second languages poses a distinctive hurdle to gain access to other parts of the life and survival in the host country i.e., Malaysia (Mohd Ali et al., 2020). Emerging research (McBrien, 2005; Scheible, 2018; Wofford \& Tibi, 2018) is showing that attention to these needs through peer programmes that are culturally and psychologically combined could have successful outcomes. This in turn appears to shorten the refugee transition period and help them to make the transition less traumatic. The refugee participants reported a greater ability to cope with resettlement after participating in an intervention utilising peer facilitators and helped the refugees to overcome settlement challenges (Mitschke et al., 2017). Nevertheless, by grooming youths to become future leaders for their community through the literacy training module, resettlement issues are hoped to be resolved to a certain extent. The literacy training module, which is interweaved with Islamic elements and values, will help to ensure its youths and substantial portion of adults to achieve literacy. Being literate in the host country's language and the English language will enhance their employment opportunities, and therefore improve their life (Mohd Ali et al., 2020).

\section{Methodology}

This section highlights the backbone of the study which includes the participants, data collection methods, instruments, and research procedures.

\section{Participants}

The sampling strategy employed for this study is the snowballing technique where the researchers identify the first participant and rely on him to introduce additional participants. With this method, the study gathered 15 Rohingya youth participants aged between 17 and 25. They were from Selangor and have been in Malaysia for more than three (3) years. All of them were employed to do menial jobs such as grass cutters, store and kitchen helpers. Being employed has given them a sense of independence which has opened up opportunities for them to get equipped with relevant skills as a way to survive in the host country. To begin with, although limited, they were able to converse in the Malay language. 


\section{Data Collection Methods, Instruments and Research Procedures}

Data were collected primarily via the qualitative method and a bit through the quantitative method. They involved document analysis, interview and survey, where the instruments used include a literacy baseline test, an interview protocol and a guided questionnaire respectively. The research procedures involved data collection dan data analysis procedures which are illustrated in figure 1 below.

\begin{tabular}{|ll|l}
$\vec{d}$ & Data Collection \\
$\tilde{w}$ & Procedures \\
$\frac{\sigma}{\alpha}$ & 1. Test \\
2. Interview & 3. Questionnaire
\end{tabular}

Figure 1. Research procedures

Figure 1 shows that there were three (3) phases in the research procedures of this study. In Phase 1 , the participants were involved in all the data collection activities beginning with the test. The baseline test consists of three (3) parts (A, B \& C) to gauge the participants' present English language literacy ability. Part $A$ comprises the Listening and Speaking components where the participants are required to respond to questions. In part $B$, they need to identify shapes, roman alphabets, and numbers. The last part is about Writing where they read or listen to the questions and write down the answers.

Next, in Phase 1 was the guided questionnaire where there were open-ended questions. The participants were assisted in answering the questions which are language literacy related. The last activity in Phase 1 was the interview. There was one round of focus group interview. The participants were put into groups of 4-5 people. The session was moderated by a research team member and the objective was to probe into their Islamic psycho spiritual practice and belief. The group interview was conducted in the Malay language for about 15-20 minutes each session, and it was recorded. All the participants completed the consent form for the 3 data collection activities and also consented for the interview session to be recorded.

In Phase 2, the data gathered were prepared for analysis. The baseline test was marked and scored, the data from the open-ended questions in the questionnaires were sorted and the interview sessions were transcribed. The data were then ready for Phase 3 where they were analysed. Frequency count was done for the test. As for the data from the open-ended questions and the interview transcripts, data were thematically analysed following the Braun and Clarke's (2006) 6-step analysis. The data were all in the Malay language. Once the extracts were chosen for the themes, they were translated into English for discussion. 


\section{Findings}

Based on the findings, a framework (Refugee-LitPsy Framework) as illustrated in Figure 2 emerged. In this framework, the two major components which are literacy (both Basic and Functional) and psychospiritual can be seen as complementing one another in the life of the participants. From the data, it was found that these two components are crucial for the survival of the participants in a new environment which is different from their country of origin. The literacy component comprises speaking, listening, reading, and writing skills, while the psychospiritual component include religious belief and religious practice when dealing with adversity to prepare the refugees to socially navigate in their host country.

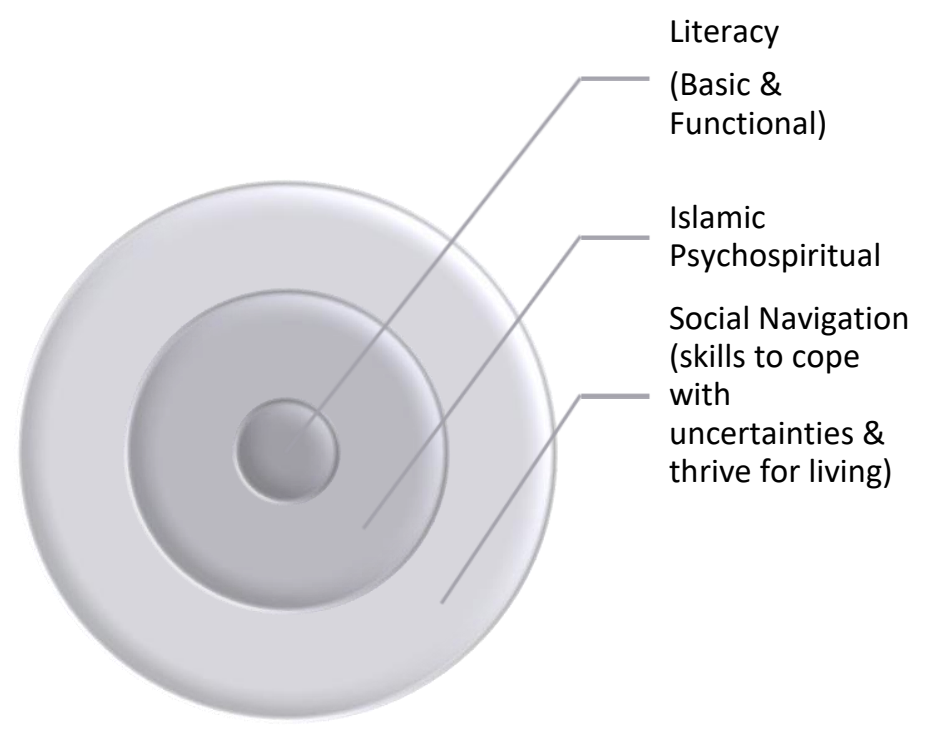

Figure 2. Refugee-LitPsy Framework

The development of the module for the Rohingya youth refugees is based on the Refugee-LitPsy Framework. However, since this paper focuses on the literacy component, we will present the findings on the literacy component and discuss the psychospiritual component only when necessary.

The literacy component of the module consists of two parts namely the basic literacy and the functional literacy part. The basic literacy part focuses on introducing the roman alphabets to the Rohingyas youth refugees because the Rohingyas' written language is different from the Roman alphabetical language system. We have shared in our previous publication that "despite the keen interests the participants have in acquiring English language proficiency, the different alphabetical systems pose problems for them" (Suraini et al. 2020, p.33). Since their writing system is very different from the roman alphabetical system, it is important that we introduce the 26 letters in the English alphabets first. Thus, this basic literacy part starts with introductory activities to the English alphabets including tracing the forms of the alphabets (i.e., the A, B, \& C) and identifying the letters. Basic words and formation of words are also introduced in this part of the module.

Most of the activities related to the basic literacy component of the module are introduction and memorisation of new words and understanding their connection to the objects around their surroundings. The second part of the module, i.e., the functional literacy part, focuses more on introducing communicative type of languages especially writing and speaking, which is designed to be more relatable to them especially in the context of getting to know the surrounding community in their host country, Malaysia, and helping them with basic communicative English skills to secure a job. So, this second part, is expected to be more 
appealing to them since later when they are relocated to a permanent country, they would want to have at least a basic mastery of the English language skills for the purpose of communicating with their new neighbours and job hunting. Part of the reason to introduce this section to them is to motivate them to continue attending the classes held and completing the module developed based on the Refugee-LitPsy Framework. Unlike the basic literacy components, in the functional literacy component, lessons would require students to choose and identify the most appropriate expressions to use for the dialogue exchange which will require more than basic identification of words and forms. The module is an opportunity to get a more customised English language education that fit their need as a community rather than the more mainstream educational (and Malaysian based) option out there.

\section{Discussion}

Literacy is generally known as the ability to read and write. However, "the current perspective tends to extend beyond a basic knowledge of written language to encompass the notion of function. Accordingly, literacy comprises not only the ability to read and write, but also the ability to use such skills to function in society" (Piccinin, et al, 2021 p.1). There are 11 units (Units 1 - 11) in the Basic Literacy section and 7 units (Units 7-18) in the Functional Literacy section. In this paper, two units (Unit 1 and Unit 3) from the Basic Literacy sections and three units (Unit 12, Unit 16 and Unit 17) from the Functional Literacy section are explicated and illustrated with some snap shots of the contents in the respective units. The following part will explain the Basic Literacy.

\section{Basic Literacy (BL)}

Basic Literacy section commences with Unit 1: Shapes O Shapes! As mentioned earlier, the specialty of the module is that it is created with learners of non-Roman alphabetical system in mind. Thus, Unit 1 is seen as a necessary opening to the module. Since the target learners are not familiar with the Roman alphabetical system, exposing them to tracing exercise seems the best opportunity to provide initial experience in recognising, and later, writing ABCs. Although some disagree that tracing helps children learn to write (e.g., Jacobs, 2020), in the case of adult learners from the non-Roman writing system background, it is helpful for learners to undergo this exercise as it prepares them for legibility, memory, and writing fluency. Moreover, Piccinin et al. (2021) stated that, "Acquiring the alphabetical principle is thus key to adult reading development too and should be reflected by appropriate training in the recognition of grapheme-phoneme correspondences" (p. 5).

In this unit too, the learners are exposed to the correct way of holding pens/pencils. After the tracing of random shapes and sizes, learners are then asked to practice tracing their names (capital and small letters). Figures $3-7$ illustrate Unit 1 of the module. 
INTERNATIONAL JOURNAL OF ACADEMIC RESEARCH IN BUSINESS AND SOCIAL SCIENCES Vol. 12, No. 1, 2022, E-ISSN: 2222-6990 @ 2022 HRMARS

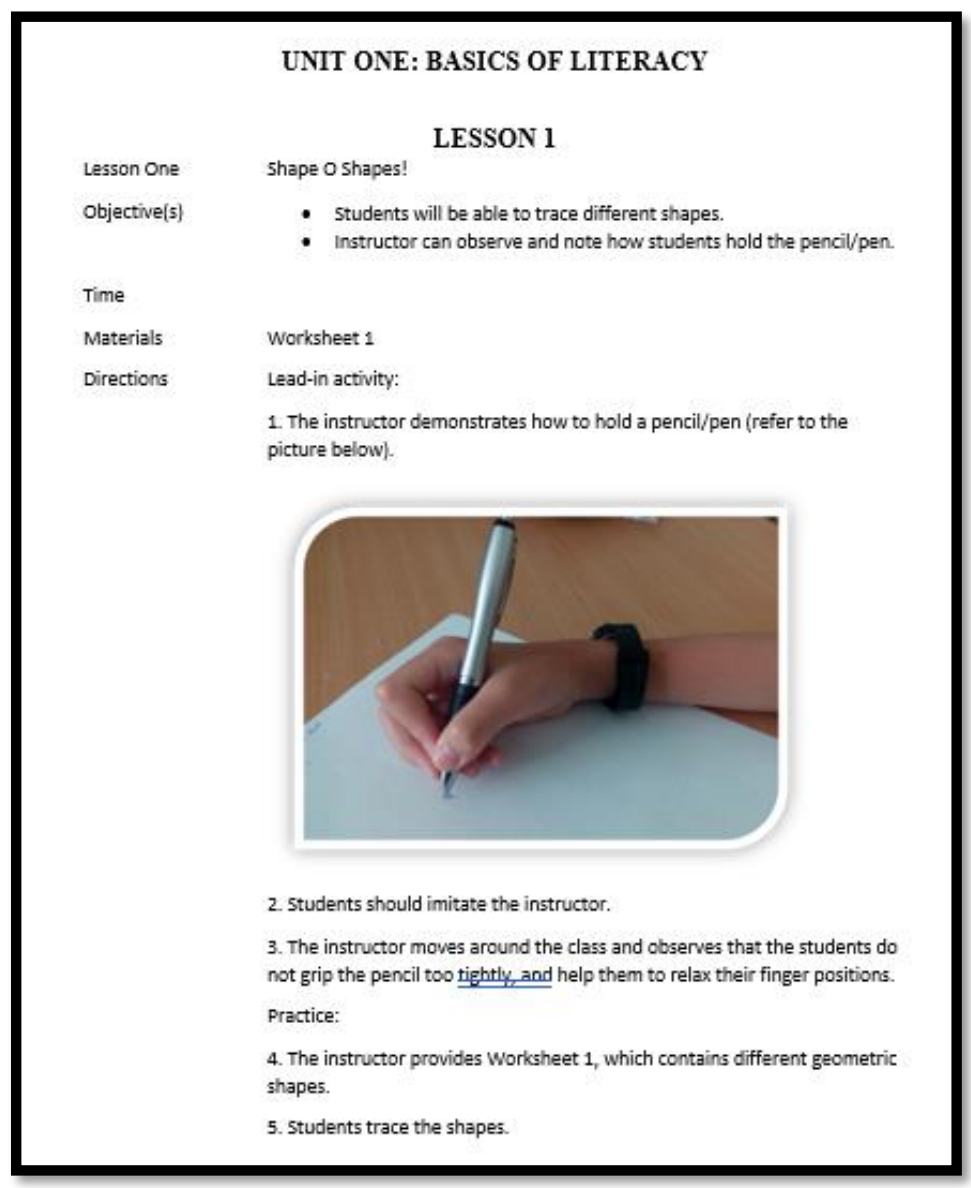

Figure 3. Snapshot of Unit 1 
INTERNATIONAL JOURNAL OF ACADEMIC RESEARCH IN BUSINESS AND SOCIAL SCIENCES Vol. 12, No. 1, 2022, E-ISSN: 2222-6990 @ 2022 HRMARS

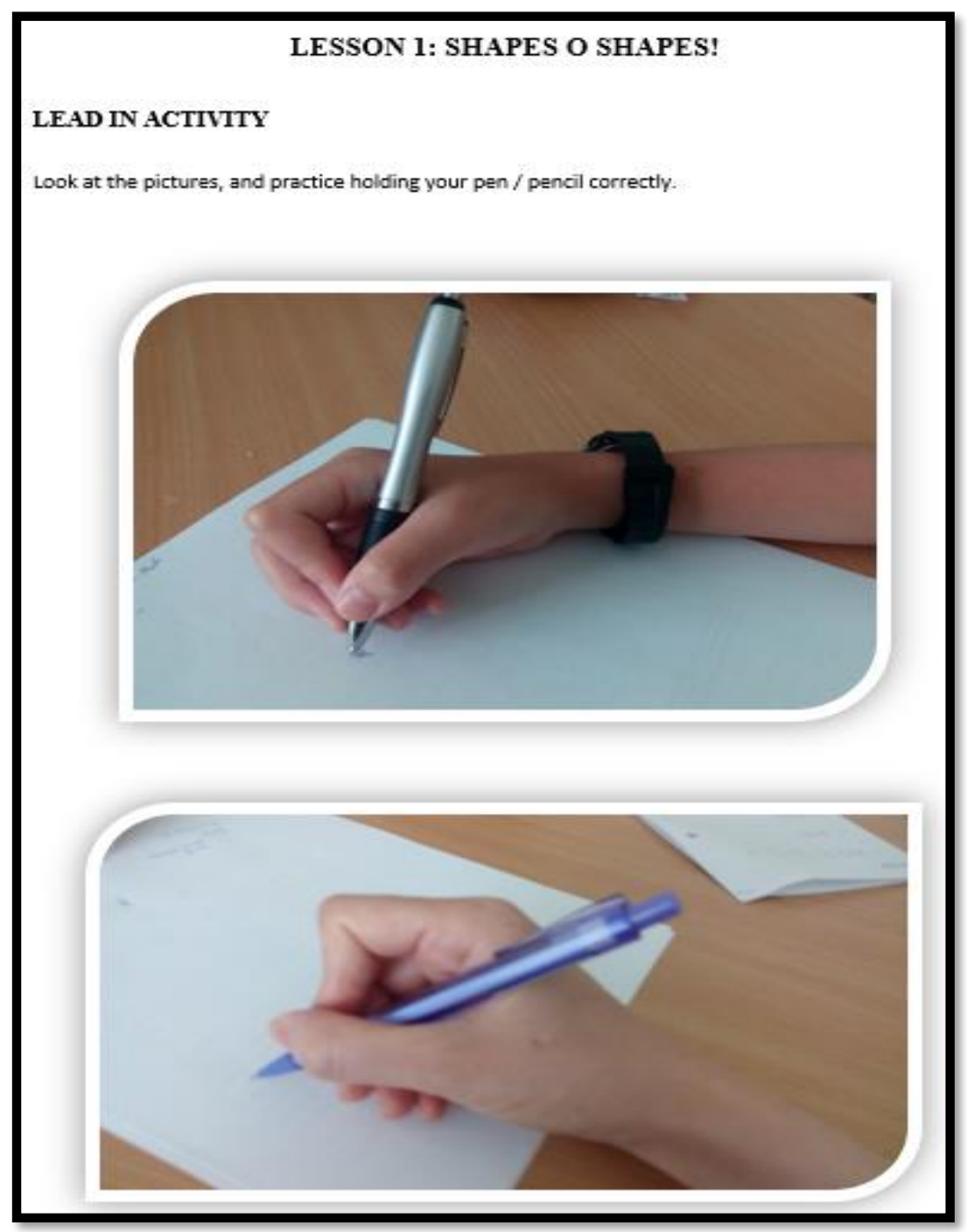

Figure 4. Snapshot of Lead in activity 


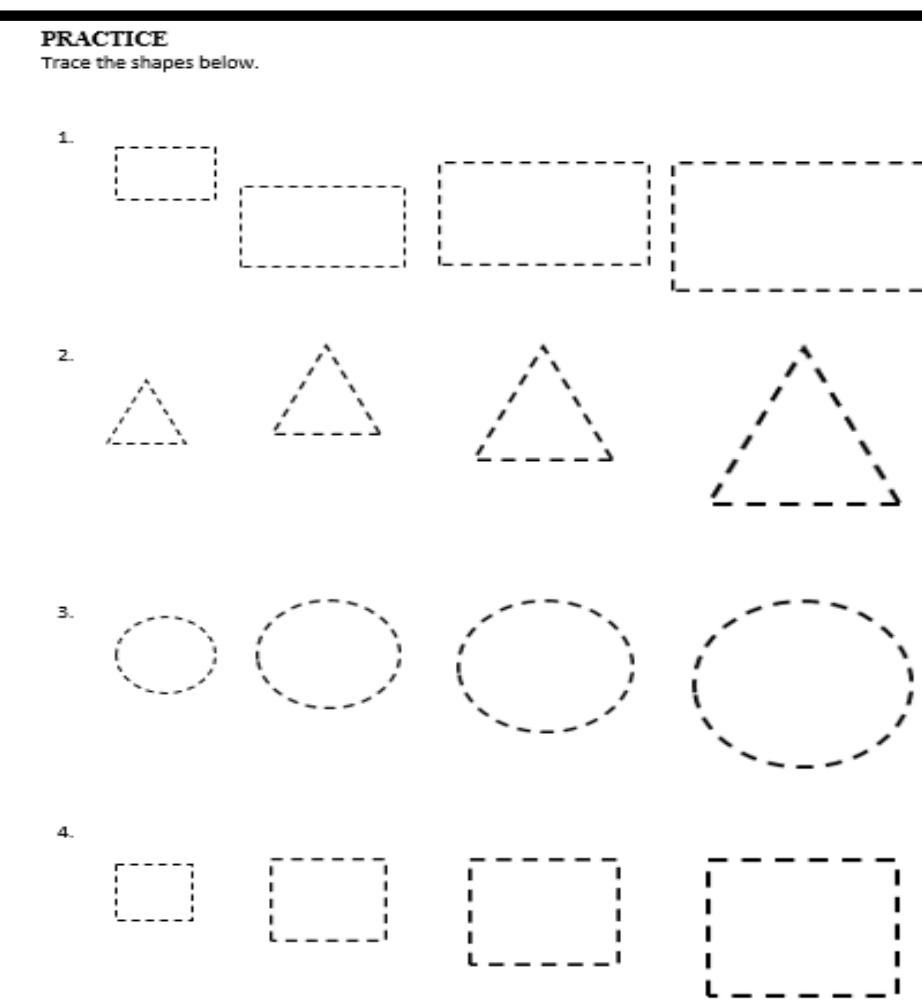

Closure

Figure 5. Snapshot of Tracing activity

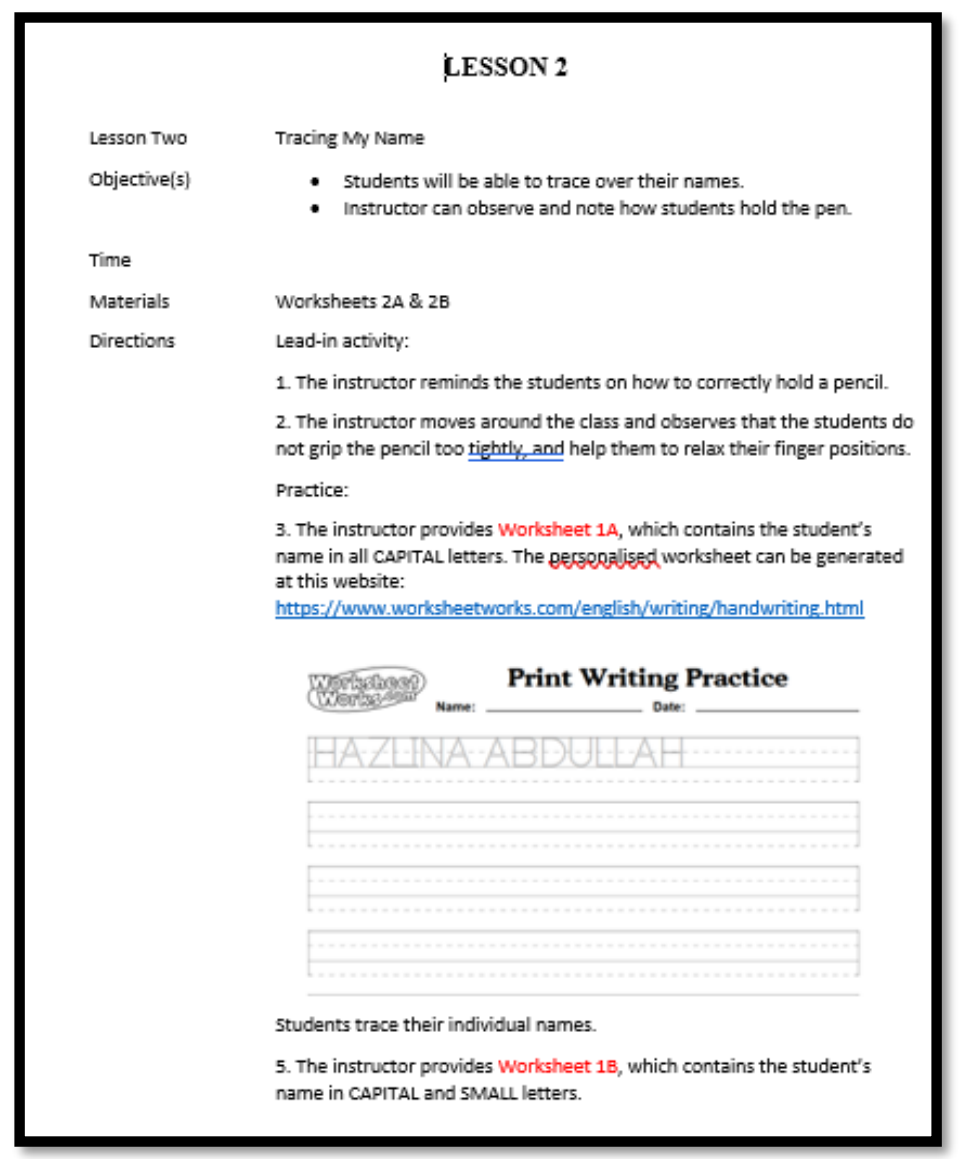


Figure 6. Snapshot of Tracing Name activity

LESSON 2: TRACING MY NAME
LEAD IN ACTIVITY
Do you remember the correct way of holding a pen / pencil?
Practice doing it again.
The instructor will move around the class and observe the way you hold your pen / pencil. Note that
you should not grip the pencil too tightly. Try to relax your finger positions.
In this lesson, you will peactises tracing your name.
PRACTICE
Your instructor will provide a handout which contains your name. Trace your name, and pacatise
writing your name correctly.
CLOSURE

Figure 7. Snapshot of Lead in activity for Tracing Names

The Literacy module resumes with another lesson, ' $M y A B C^{\prime}$, with the objective of identifying letters or alphabets. This is done through some teaching aids such as $A B C$ songs, $A B C$ poster and $A B C$ magnetic letters. Figures 8 and 9 show the excerpts of the module.

\section{LESSON 3}

Lesson Three
Objective[s]
Students will be able to identify letters / alphabets.
Mime
Materials song; ABC Poster; ABC magnets
Lirections
1. The instructor tells the class that there are 26 alphabets altogether (A-Z),
and inform the students they are going to listen to a song.
2. The instructor plays an ABC song and invites the students to sing along.
https://www.youtube.com/watch?v=85fifstrfPI
Practice:
2. The instructor puts up a big Alphabet poster on the board.
3. The instructor calls out students to match the ABC magnets with the
letters in the poster.

Figure 8. Snapshot of Lesson 3 


\section{LESSON B: MY ABC}

\section{LEAD IN ACTIVITY}

How many characters are there in your native language?

Do you know how many alphabets are there in the English language?

There are 26 alphabets altogether in the English language (from ' $A$ ' to ' $\mathrm{Z}$ '). You will listen to the $A B C$ song played by your instructor.

After listening to the ABC song, you can sing along to fariliarigeyourself with the alphabets used in the English language.

\section{PRACTICE}

Your instructor will put up a big Alphabet poster on the board.

5/he will call out students to match the $A B C$ magnets with the letters in the poster.

\section{CLOSURE}

The instructor nominates students to say out the alphabets s/he randomly shows to the class.

Figure 9. Snapshot of Lead in activity of Lesson 3

Progressing from the introduction lesson of $A B C s$, the Basic Literacy section moves further to the word level. This lesson invites learners to relate the beginning sound of certain objects brought in by the facilitator into the respective $A B C$ letter boxes (refer to Figure 10). This extends and increases learners' understanding about the letters they have learnt in the previous lesson. 


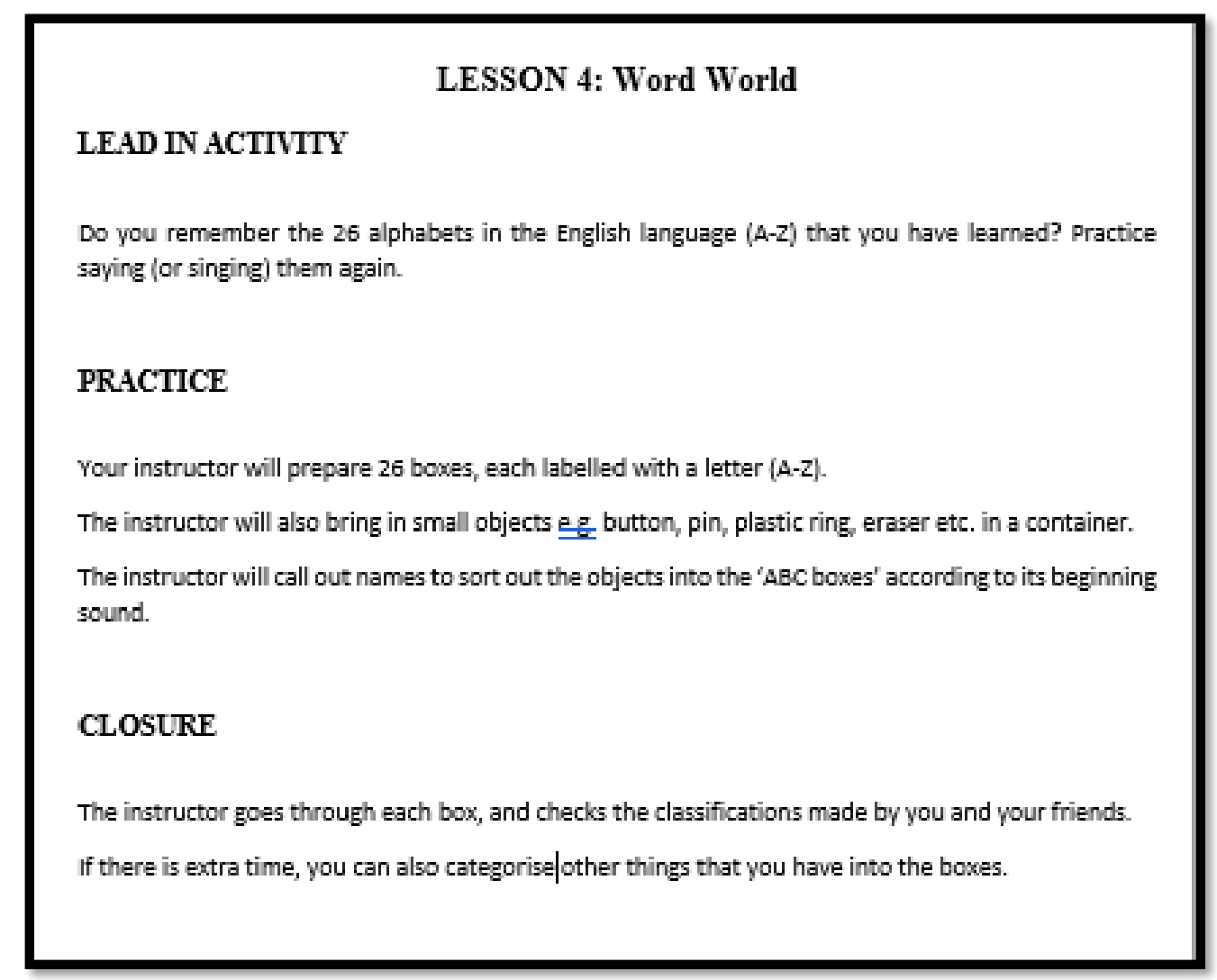

Figure 10. Snapshot of Lesson 4

In sum, the Basic Literacy (BL) section of the module outlines the necessary lessons suited to the needs of the learners - Rohingya young adult refugees-those who hail from the non-Roman script background. The lessons in the basic literacy section are in line with a study by Trupke-Bastidas and Poulos (2007) on learning English Language among non-roman alphabet background adults, "proposing an integrated approach that does not do away with phonics ... The findings reported seem to be promising, as at the end of the program, participants showed improvement both in the area of decoding and in phonemic awareness in English" (p. 16). Thus, step-by-step literacy lessons-starting from the shape tracing activity, tracing names, identifying the Roman alphabets up to recognising the sounds and relating them to the letters are designed, and hoped to build the learners' basic literacy skills to help them survive and endure their tough journey in the host country.

\section{Functional Literacy (FL)}

This section describes the second part of the module which is the Functional Literacy (FL). A functional approach to language "asserts that we need to learn how to choose our language to meet the particular needs of a situation" (Ewing, 2001, p. 1). It is also recommended in a study by Condelli and Wrigley (2006) that communicative and realistic language materials, especially real-life dialogues using authentic language assist the grasp of the language among non-roman alphabet illiterate adults.

Hence, the Functional Literacy section commences from functional language at the micro level (self and neighbours) to the meso level (Directions, Phone calls, Grocery Stores, Clinics) and the macro level (finding jobs) using interactive, real-life dialogues and contexts to assist in grasping basic functional phrases/ language to be used in daily routines. 
In this section, three units (Unit 12- Who am I?, Unit 16-Grocery Stores, Unit 18Finding Jobs) are explicated with snapshots from the module. The first unit in this section (Unit 12) is about 'Self' which is designed to tap on information about their lives (plans, current obstacles, their concerns/future plans) then transform their life stories into a vibrant, graphic timeline.

Who am I?

\begin{tabular}{|l|l|}
\hline \multicolumn{1}{|c|}{ Reflection } & \\
\hline $\begin{array}{l}\text { Where Have You } \\
\text { Been in } \\
\text { Your Lifetime? }\end{array}$ & \\
\hline $\begin{array}{l}\text { What defines } \\
\text { you? }\end{array}$ & \\
\hline $\begin{array}{l}\text { What are your } \\
\text { goals for this } \\
\text { year and } \\
\text { the future? }\end{array}$ & \\
\hline $\begin{array}{l}\text { What obstacles } \\
\text { have you } \\
\text { overcome? }\end{array}$ & \\
\hline $\begin{array}{l}\text { What do } \\
\text { you really } \\
\text { care about? }\end{array}$ & \\
\hline
\end{tabular}

Figure 11. Snapshot of Unit 12

The follow up activity from Figure 12 is to discuss the possible ways to cope with obstacles and infuse the importance of believe in faith. At this micro level topic which focuses on oneself and being, it is expected that the participants would open up to share their problems / concerns and foresee the possible way forward through the lens of religion or psychospiritual beliefs.

The next meso level topic, Unit 16 - At the Groceries, is designed with the aim to learn names of things at a grocery store and phrases to be used to communicate with the cashier. This unit is considered as the meso level context because it exposes the participants to a situation beyond 'self and neighbours'. Figures $12-14$, illustrate Unit 16 of the module: 
Lead-in activity:

1. The instructor shows a basket full of things he/she brought from a grocery store.

2. The instructor asks each student to pick one item from the basket. Each item should have a price tag attached.

3. The instructor asks the students to guess the name of the item they are holding. Students can discuss or search the name of the item (in English) from the internet.

Practice:

2. The instructor distributes hand-out $15 \mathrm{~A}$ and discuss names of items which can be found at a grocery store with the students.

3. The instructor also ask the students to check the name of the items from hand-out 15A

4. The instructor asks students to work in pairs and practice role playing between a customer and cashier using hand-out 15B. The total price in the dialogue must be changed according to the items hold by the students in class.

Closure:

4. The instructor will evaluate the presentation and give feedback on how well you use the phrases in the role play.

Figure 12. Snapshot of Unit 16

Items at the grocery store

Look at the pictures and identify the items. Discuss with your instructor about the items in the pictures.
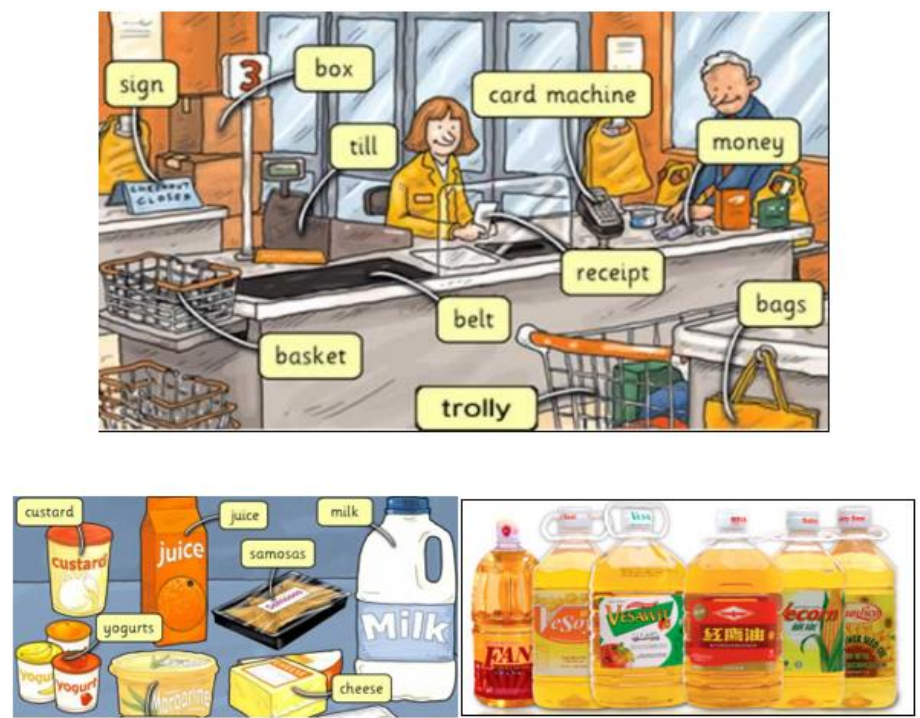

Figure 13. Snapshot of naming items 
Dialogue with the cashier

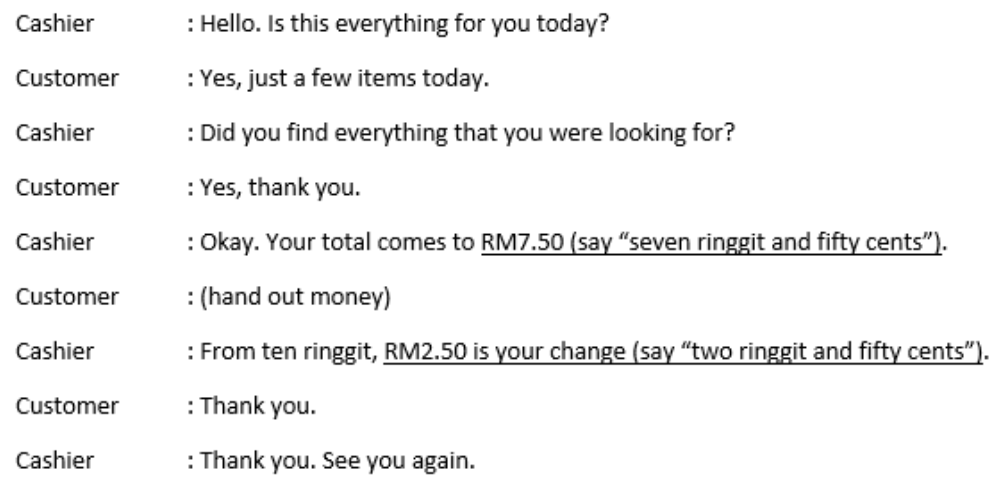

Source: https://www.slideshare.net/joeldaldrich/cashiers-communicative-english

Figure 14. Snapshot of dialogue activity

The last unit in this module is on Job Application, Unit 17. This is a macro level topic as finding for jobs or doing job application is a context which is outside their daily routines and moving towards different circle of community. The figures below illustrate Unit 17:

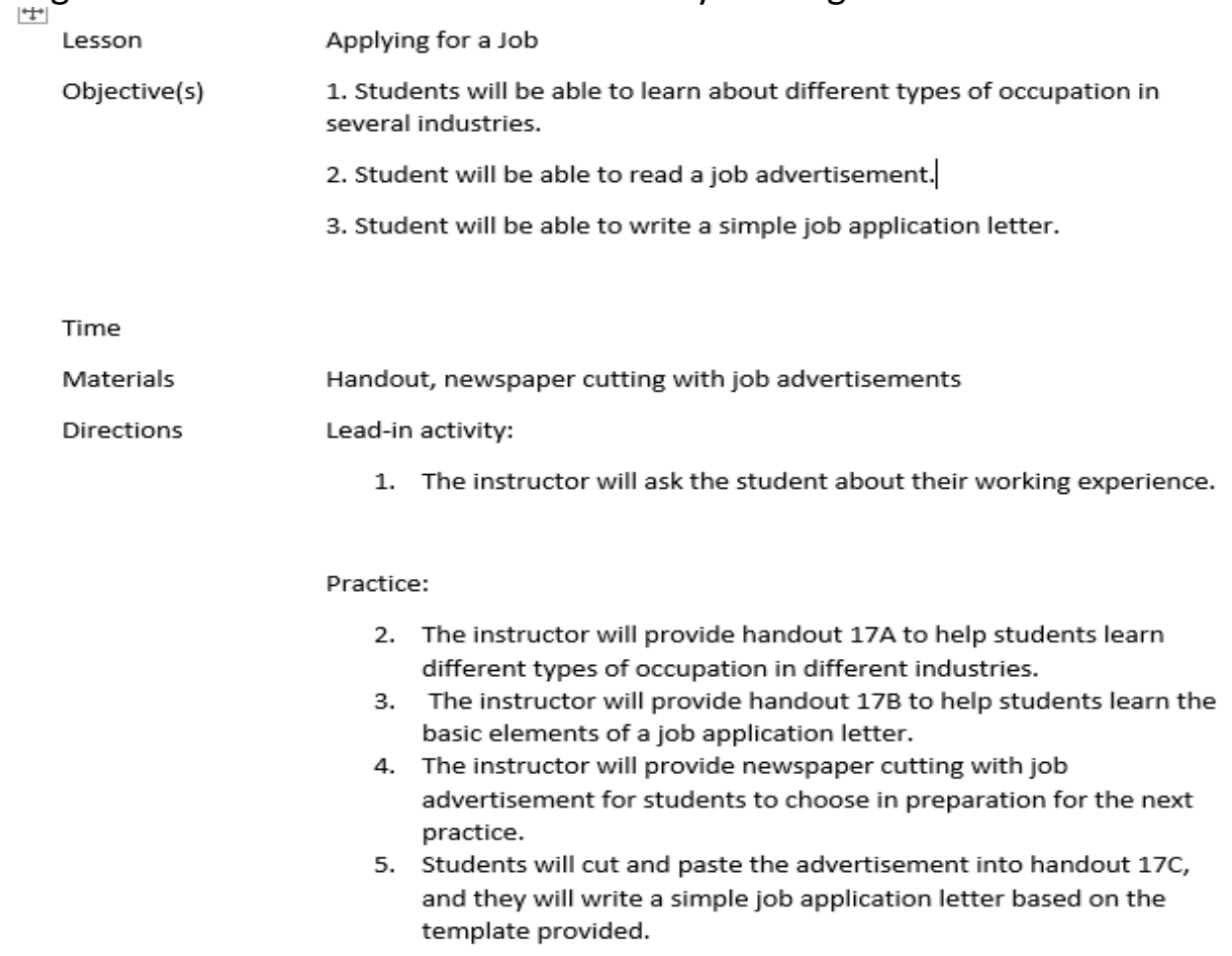

Figure 15. Snapshot of Unit 17 
Below is a list of industries typically included on job applications:

\begin{tabular}{|l|l|l|}
\hline Manufacturing & $\begin{array}{l}\text { Production supervisor, } \\
\text { machinist }\end{array}$ \\
\hline $\begin{array}{l}\text { Restaurant and } \\
\text { Hospitality }\end{array}$ & $\begin{array}{l}\text { Chef, kitchen } \\
\text { assistant }\end{array}$ & $\begin{array}{l}\text { Retail assistant, } \\
\text { retails sales manager }\end{array}$ \\
\hline Retail &
\end{tabular}

Source: https://www.workingmother.com/momlife/13709624/what-does-industry-mean-on-a-jobapplication/ \& https $/ /$ joboutlook.gov.au/Industry.aspx

Figure 16. Snapshot of jobs activity

Sample \#1

[Your Name]

[Street Address]

[City, ST ZIP Code]

20 October 2021

[Recipient Name]

[Title]

[Company Name]

[Street Address]

[City, ST ZIP Code]

Application for the post of

Dear (recipient name),

I was pleased to hear from you regarding my recent application for your open [job title] position. In response to your request, I have attached my employment and salary history. I consider salary negotiable based upon the job responsibilities.

If you have additional questions or would like to schedule an interview, please call me at [phone number]. I look forward to hearing from you.

Sincerely,

|

(Your name)

Figure 17. Snapshot of letter writing activity

The illustrations of the contents of the module [the Basic Literacy (BL) and Functional Literacy (FL)] are capsulated in figure 18. 


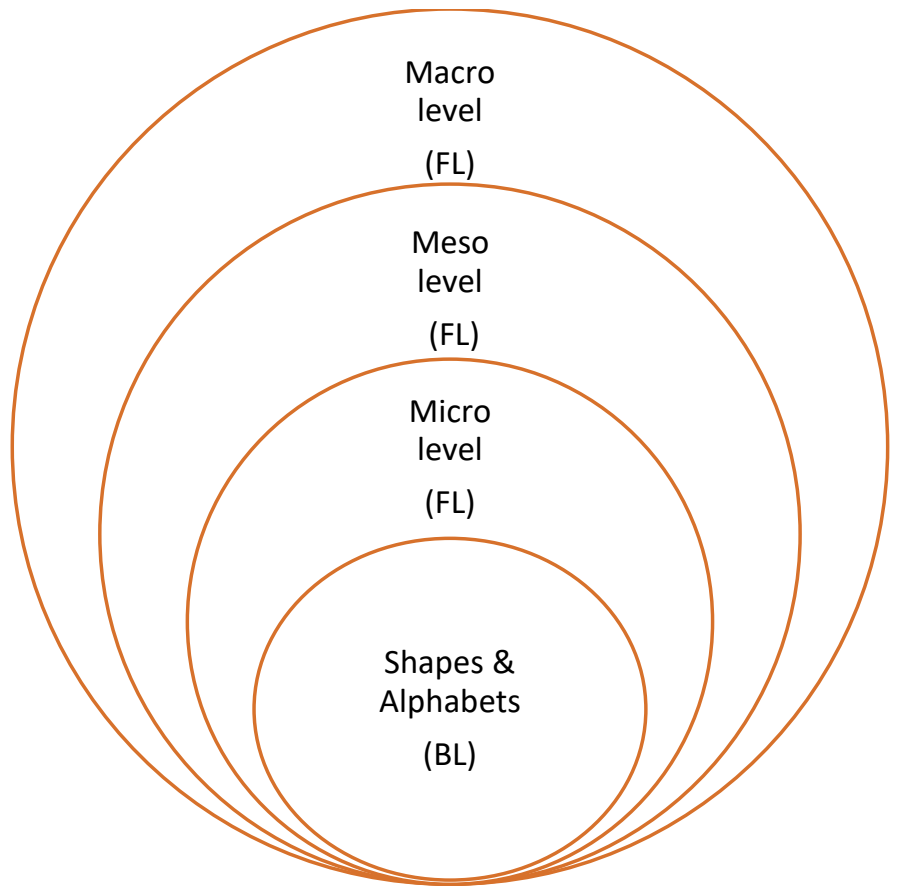

Figure 18. The content summary of the Ref-LitPsy module

The module is designed holistically starting from the basic shapes and tracing to Functional Language use ranging from the micro level to meso level and later to the macro level contexts. The different levels or contexts in this module are expected to help the participants to use simple language phrases to function well in their daily routines. The development of this module which is also based on a literacy-psychospiritual framework as discussed in the earlier section of this article, would assist the non-alphabet literates and semi-literates to learn the literacy basics and functional phrases to thrive in the host country.

\section{Conclusion}

In summary, this paper describes the Ref-LitPsy Module: An Integrated LiteracyPsychoeducational Module for Youth Refugees. It is developed following a baseline literacy study conducted with Rohingya youth refugees. The Ref-LitPsy module consists of two main areas which are literacy and psychospiritual counselling approach to assist Rohingya youth refugees in Malaysia to be able to use the English language for every-day use in the country. The literacy component engulfs a more comprehensive definition of literacy that includes speaking, listening, reading, and writing skills, as well as their functions in real-life situations. The literacy constituent is divided into two parts: basic literacy and functional literacy. The Basic Literacy component focuses on basic skills such as getting accustomed to Roman alphabets as the Rohingya people come for non-Roman alphabets background. Apart from that, the component focusses on simple language forms and functions such as identifying words related to transportation, food and colours, telling time and identifying the days of the week. The second part is Functional Literacy that concentrates on communicative skills especially in everyday and employment settings. It trains the participants to function in daily settings such as making a telephone call, knowing your neighbours, and buying groceries.

The Ref-LitPsy module can have a significant impact on the refugees as well as Malaysia as the host country. The module benefits the refugees as it can help the refugees to learn basic English to be used in daily situations. Through this, they will have the support to survive living in a country that is foreign to them in terms of literacy and culture. With their 
increased knowledge, it is hoped that they will feel less threatened in the new host country, and they have a better chance of being employed. As for the host country, Malaysia, the increased knowledge of the English language among the Rohingya youth refugees could lessen the economic and social burden. A high percentage of refugees securing jobs could be beneficial to the resettlement progress of the refugees. At the same time, by utilising this module, Malaysia is fulfilling its social responsibility by ensuring inclusive and equitable quality education for all as outlined in SDG4.0. In addition, this effort correlates with UNHCR's Refugee Education 2030 policy that aims to enhance the learning of the refugees through collaboration with the hosting communities. In conclusion, this module definitely ticks all the right boxes in terms of impacting the refugees and the host country, Malaysia. The module is revised from time to time to ensure its currency, suitability, and appropriateness.

\section{Acknowledgement}

This work was supported by Universiti Sains Islam Malaysia under the Matching Grant scheme USIM/MG/MYCARE/FPBU/055012/70818.

\section{References}

Benseman, J. (2014). Adult refugee learners with limited literacy: Needs and effective responses. Refuge, 30(1), 93-103. https://doi.org/10.25071/1920-7336.38606

Lee, C. (2020). Negotiating dual identities: A case study on the narratives of two Myanmar refugee youths living in Malaysia. Kajian Malaysia, 38 (2), pp. 61-90.

Lee, C., and Don, Z. M. (2021). Belonging and identity in the narratives of two secondgeneration refugee youths in Malaysia. In Zawawi Ibrahim et al. (eds.), Discourses, Agency and Identity in Malaysia, Asia in Transition 13, https://doi.org/10.1007/978981-33-4568-3_14.

Ewing, R. (2001). What is a functional model of language? Marrickville, N.S.W: Primary English Teaching Association

Jacobs, J. (2020). To trace or not to trace? The Learning Professor. https://learningprofessor.com/2020/02/12/to-trace-or-not-to-trace/

Khairi, A. (2010). Managing the challenges of refugees and their rights in Malaysia 1. The First International Conference on Human Rights in Southeast Asia, 1-12. http://www.ntu.edu.au/faculties/lba/schools/Law?apl/Retreating/shoesmith.htm

McBrien, J. L. (2005). Educational needs and barriers for refugee students in the United States: A review of the literature. Review of Educational Research, 75(3), pp. 329-364. https://doi.org/10.3102/00346543075003329

McKeary, M., \& Newbold, B. (2010). Barriers to care: The challenges for Canadian refugees and their health care providers. Journal of Refugee Studies, 23(4), pp. 523-545. https://doi.org/10.1093/jrs/feq038

Mitschke, D. B., Praetorius, R. T., Kelly, D. R., Small, E., \& Kim, Y. K. (2017). Listening to refugees: How traditional mental health interventions may miss the mark. International Social Work, 60 (3), pp. 588-600. https://doi.org/10.1177/0020872816648256

Ali, M. S., Baharun, H., Abdullah, H., Saad, S. M. N., Behak, P. F., Ismail, H., Idrus, M., Farhana, D., \& Zakaria, Z. M. (2020). An emerging framework: Literacy training module for social navigation of refugees. International Journal of Language Education and Applied Linguistics, 10 (1), pp. 41-48. https://doi.org/10.15282/ijleal.v10.3934 
Nungsari, M., \& Flanders, S. (2018). A comprehensive study of Rohingya construction workers in Peninsular Malaysia and recommendations for a future work pilot programme. Retrieved from http://www.melatinungsari.com/uploads/2/3/6/3/23631450/finalreport-mnsf.pdf.

Scheible, J. (2018). Literacy training and German language acquisition among refugees: Knowledge of German and the need for support among integration course attendees learning a second alphabet and those with no literacy skills. Edition 1/2018 of the Brief Analyses of the Migration, Integration and Asylum Research Centre of the Federal Office for Migration and Refugees, Nuremberg, 1-13.

Strategic Social Policy Group. (2008). Diverse communities - exploring the migrant and refugee experience in New Zealand. Ministry of Social Development.

Trupke-Bastidas, Julie, and Andrea Poulos. 2007. Improving literacy of L1-non-literate and L1literate adult English as a second language learners. MinneTESOL/WITESOL Journal 24. Available online: http://minnetesoljournal.org/wp-content/uploads/20 18/06/TESOL2007.pdf

UNHCR. (2019). Refugee education 2030: A strategy for Refugee Inclusion. Testing and Inclusive Schooling, pp. 152-169.

UNHCR. (2021). https://www.unhcr.org/en-my/figures-at-a-glance-in-malaysia.html accessed on 27 August 2021.

UNHCR. (2001-2021). What is a refugee? https://www.unhcr.org/en-my/what-is-arefugee.html

Wardeh, M., \& Marques, R. C. (2021). Sustainability in refugee camps: A systematic review and Meta-Analysis. Sustainability (Switzerland), 13 (14). https://doi.org/10.3390/su13147686

Wofford, M. C., \& Tibi, S. (2018). A human right to literacy education: Implications for serving Syrian refugee children. International Journal of Speech-Language Pathology, 20(1), 182-190. https://doi.org/10.1080/17549507.2017.1397746 